[Aus dem hygienischen Institut zu Berlin.]

\title{
Ueber den Vibrio Metschnikoff und sein Verhältniss zur Cholera asiatica.
}

\author{
Von \\ Dr. R. Pfeiffer, \\ Stabsarzt und Assistent. \\ (Hier\%u Tnf. III.)
}

In seinen Untersuchungen über den von ihm so benannten Vibrio Metschnikoff hatte Gamaleia ${ }^{1}$ sehr weit gehende Analogieen sowohl im morphologischen, als biologischen Verhalten zwischen diesem Mikroorganismus und dem Koch'schen Kommabacillus behauptet, Aehnlichkeiten, welche jede Schranke zwischen beiden Bacterienspecies zu verwischen schienen. Da der Vibrio Metschnikoff ein beständiger Bewohner Europas sein sollte und auch in eine nahe Beziehung zu der sporadischen Form der Cholera nostras gebracht wurde, so würde die diagnostische Bedeutung der Cholerabacillen eine .wesentliche Einschränkung erfahren müssen, vorausgesetzt, dass die von Gamaleia behaupteten Thatsachen sich bestätigten. Eine Nachprüfung der Ergebnisse des russischen Forschers war somit ein Desiderat von der höchsten Wichtigkeit, und ich sage hiermit Hrn. Professor Metschnikoff, durch dessen gütige Vermittelung ich in den Besitz einer Cultur der Gamaleia'schen Vibrionen gelangt bin. meinen verbindlichsten Dank.

Was zunächst die Morphologie des Vibrio M. anbetrifft, so stellt er sich ebenso wie die Cholera asiatica als leicht spiralig gekrümmtes Stäbchen dar, welches mit Fug und Recht den Namen Kommabacillus beanspruchen kann; doch überzeugt man sich an Präparaten und Photogrammen, welche

1 Annales de l'Institut Pasteur. 1888. p. 482 u. 552. 
in durchaus identischer Weise aus gleichaltrigen frischen Culturen hergestellt sind, dass der Vibrio M. im Durchschnitt etwas kürzere, dickere und stärker gekrümmte Stäbchen bildet, als der Cholerabacillus. Gelegentlich, besonders im Thierkörper, sind die einzelnen Vibrionen sehr kurz, fast kokkenartig. Im hängenden Tropfen hat der Vibrio M. eine sehr rapide Eigenbewegung, die aber auch nicht völlig vergleichbar ist mit dem eigenthümlichen mückenschwarmartigen blitzschnellen Tanzen und Wirbeln der Cholerabacillen. Als Fortbewegungsorgan besitat jeder Bacillus einen langen, ausserordentlich feinen Geisselfaden, ${ }^{1}$ der unter bestimmten Verhältnissen durch Färbung mit Fuchsin oder Gentianariolett sichtbar gemacht werden kann. Eigenthümlich ist dem Vibrio M. eine entschiedene Neigung zur Spirillenbildung. Man findet dabei eine ziemliche Mannigfaltigkeit der Formen, kurze und lange, dicke und dünne, regelmässig spiralig gewundene und unregelmässig geknickte und gestreckte Spirillen.

Der Fürbung sind die Gamaleia'schen Vibrionen leicht zugänglich. Bei Anwendung dünner Färbflüssigkeiten färben sich am intensivsten die Enden der einzelnen Bacterien, während die Mitte fast farblos bleibt. Es entstehen so Bilder, die täusehend den Hühnercholerabacterien $\ddot{\text { ähn- }}$ lich sind. Manchmal sieht man auch Spirillen, in welchen mit regelmāssigen Zwischenräumen gefärbte und ungefärbte Partieen abwechseln. Mit Sporenbildung haben diese Lücken sicher nichts zu thun, auch vermochte ich nie ächte Sporenbildung bei dem Vibrio M. zu constatiren, während Gamaleia bei seinen Vibrionen unter nicht genauer präcisirten Verhältnissen Sporen beobachtet haben will, welche der Sporendoppelfärbung zugänglich waren. Jedenfalls finde ich in seinen Arbeiten nicht erwähnt, ob diese angeblichen Sporen ihre Sporennatur auch durch vermehrte Widerstandskraft gegenüber desinficirenden Agentien u. s. w. documentirt haben. So lange möchte ich diese Frage in suspenso lassen; immerhin wäre die Constatirung einer ächten endogenen Sporenbildung ein wichtiges morphologisches Kriterium zur Unterscheidung zwischen .Vibrio M. und Chulera asiatica.

Auf Agar-Agar gedeiht der Vibrio M. sehr gut und bildet dort bei Brūttemperatur innerhalb weniger Stunden gelbliche bis gelbbräunliche Auflagerungen in ganz gleicher Weise wie Deneke's und Finkler's Bacillen und wie die Cholera asiatica. Auf Kartoffelscheiben gedeiht der Vibrio M. nur spärlich und nur bei Brüttemperatur. Der so entstehende dünne Culturrasen hat eine braune Färbung. Die Bouillon wird sehr

1 Photogramme derselben werden in dem von Fränkel und Pfeiffer herausgegebenen Mikrophotographisehen Atlas der Basterienkunde veröffentlicht werden. 
rasch, bei $37^{\circ} \mathrm{C}$. schon nach wenigen Stunden intensiv getrübt. Innerhalb 24 Stunden bildet sich dann auf der Oberfläche der trübe bleibenden Bouillon eine dünne weissliche Decke. Auf Zusatz nitritfreier Salzsäure oder Schwefelsäure entsteht schon nach 24 Stunden in der Bouillon eine deutliche Rosa- bis Purpurfärbung, die von der bekannten Cholerareaction nicht zu unterscheiden ist. Die Intensität der Fârbung wächst mit dem Alter der Culturen. Bei älteren, 8 bis 14 Tage fortgezũchteten Metschnikoff-Bouillonculturen ist die Reaction ausserordentlich intensiv, doch hat die entstehende Färbung, wie schon Gamaleia angiebt, einen in das Gelbrothe spielenden Farbton. Wir lernen also in dem Vibrio M. einen Mikroorganismus kennen, der unter sonst gleichen Verhältnisseu die bisher für die Cholera asiatica als charakteristisch betrachtete Farbenreaction gleichfalls giebt. Zum Glück besitzt dieser Vibrio soustige Eigenschaften, welche, wie wir später sehen werden, seine Unterscheidung von der wirklichen Cholera leicht machen.

In Gelatinestichculturen bei Zimmertemperatur zeigt der Vibrio M. ein ziemlich rasches Wachsthum; jedenfalls überflügelt er gleichzeitig angelegte Choleraculturen um ein Beträchtliches. Seine Wachsthumsenergie würde etwa der des Deneke'schen Vibrio entsprechen. Der Allblick 24 Stunden bis 3 Tage alter Gelatinestichculturen erinnert übrigens ausserurdentlich an das Bild etwa doppelt so alter Choleraculturen.

In Gelatineplatten zeigen sich dem blossen Auge die ersten Anfünge der Colonieenbildung schon nach 16 Stunden als kleine weisse Pünktchen, die unter Gelatineverflüssigung rasch an Umfang zunehmen. Die Verflüssigung der Gelatine macht nun bei der Mehrzahl der Colonieen rasche Fortschritte, so dass schon nach 24 bis 30 Stunden ziemlich grosse kreisrunde, mit gleichmässig trüber Flüssigkeit gefüllte Schalen entstehen, die schliesslich zusammenfliessen. Derartige Colonieen ähneln in hohem Grade den bekannten Colonieen des Finkler'schen Bacillus. Andere Colonieen wieder gelangen erst viel später, nach 48 Stunden, zu einer makroskopisch sichtbaren Verflüssigung der Gelatine und stellen sich alsdann als weisse Punkte dar, welche im Centrum einer kleinen kreisrunden, mit klar verflüssigter Gelatine gefüllten Höhlung liegen, ein Anblick, der dem typischen Bilde älterer Choleracolonieen sich annähert.

Tbenso verschieden wie das makroskopische ist das mikroskopische Verhalten der Gelatineplattencolonieen. Betrachten wir nun zunächst das Aussehen der stark verflüssigenden Colonieen. Nach 24 Stunden gewahrt man Häufchen von ziemlich groben, das licht stark brechenden Bröckeln, die in dünnen Schichten eine hellgelbe, in dickeren eine dunkel gelbbräunliche Farbe besitzen. Der Rand dieser Colonie ist von einer kreisrunden Zone feiner, in ridiürer Richtung ausstrahlender Fïden umgeben. 
Wird die Colonie älter, so dehnt sich der Strahlenkranz in concentrischem Fortschreiten immer weiter aus, während im Inneren die Bröckel und Körnchen durch klare verflüssigte Gelatine mehr und mehr aus einander gedrängt werden. Schliesslich stellt sich die Colonie als ziemilich grosse, von einem feinen Strahlenkranz umgebene Verflüssigungszone dar, in deren Innerem feine Bröckchen und Körnchen in klarer Flüssigkeit suspendirt sind.

Andere Colonieen besitzen in der Jugend eine heilgelbliche Farbe und schwach gewellten Contour, der wie mit flachen Wärzchen besetzt ist. Die Gelatine wird hier beim weiteren Heranwachsen nicht so rapide verflüssigt und es treten durch das Einsinken der eigentlichen Colonie in den Verflüssigungstrichter Bilder auf, die sehr an das Aussehen der Choleracolonieen erinnern. Wieder andere Colonieen stellen sich als bräunlichgelbe, fein granulirte Häufchen dar, von deren Oberfläche zarte Schlingen in die im Uebrigen klare Verflüssigungszone hineinragen. Untersucht man solche Colonieen an gefärbten Trockenpräparaten, so gewahrt man, dass sie fast ausschliesslich aus wohl ausgebildeten Spirillen zusammengesetzt sind. Schliesslich finden sich hin und wieder Colonieen, welche anscheinend die Gelatine gar nicht verflüssigen und die in der Tiefe der Gelatine als hellgelbe, kreisrunde oder leicht gewellte und oft concentrisch geschichtete Scheiben erscheinen von sehr feinkörnigem Gefüge, während die oberflächlichen Colonieen als hellweisse, sehr zarte und fein granulirte Schichten mit rundlichem und mehr oder weniger gelapptem Contour der Gelatine aufliegen. Im Laufe der Zeit, nach 4 bis 5 Tagen, kommt es jedoch auch hier zu einer deutlichen Verflüssigung, wodurch das Bild einem der vorher beschriebenen Typen sich annähert.

Der Vibrio M. bietet also, wie man sieht, recht erhebliche Formenunterschiede dar in Bezug auf sein Colonieenwachsthum in der Gelatineplatte. Diese Unterschiede fallen so stark in das Auge, dass ich bei meinen ersten Untersuchungen der frisch von Paris erhaltenen Agarculturen zunächst ernsthaft im Zweifel war, ob ich nicht ein Gemisch von mindestens zwei verschiedenen Arten vor mir hätte. Ich isolirte daher die beiden am weitesten differirenden Formen, einerseits die stark verflüssigenden Colonieen vom Finkler-Typus, die ich als $M I$ bezeichnete, und daneben das andere Extrem, die am langsamsten verflüssigende Form als $M I I$. Meine Monate lang fortgesetzten Untersuchungen haben mich nun überzeugt, dass beide Formen in der That nur Spielarten sind, die sich ausschliesslich durch ihre Gelatine verflüssigende Kraft unterscheiden, im Uebrigen aber in sämmtlichen sonstigen Eigenschaften, in ihrem Verhalten innerhalb und ausserhalb des Thierkōrpers absolut identisch sind. Noch mehr, es ergab sich, dass immer wieder in den $M I I$ - 
Culturen, wemn diese nach Ablauf einiger Wochen von Neuem mit dem Plattenverfahren untersucht wurden, Colonieen von dem Typus $M I$ auftreten, während umgekehrt in den $M I$-Platten gelegentlich Colonieen auftauchten, deren Verflüssigungsvermögen erheblich geringer war, als das der übrigen Colonieen. Wodurch diese Variationen herrorgebracht werden, weiss ich zur Zeit noch nicht zu sagen. Ich dachte zunächst an einen Einfluss der Winterkälte, welcher die von Paris Anfangs Februar bei strengem Frost abgeschickten Culturen doch jedenfalls während des Transportes längere Zeit ausgesetzt waren. Diese Vermuthung wurde durch den Versuch als nicht stichhaltig dargelegt. Ich setzte $M I$-Culturen 24 Stunden lang in einer Kältemischung einer Temperatur aus, die zwischen minus $20^{\circ} \mathrm{C}$. und $0^{\circ}$ schwankte. Die mit dieser Cultur vor und nach der Kälteeinwirkung besäten Gelatineplatten liessen jedoch einen deutlichen Unterschied in der verflüssigenden Kraft der Colonieen nicht erkennen. Ich mōchte hier daran erinnern, dass Fritsch ${ }^{1}$ ganz ähnliche Variationen der Colonieenform bei dem Finkler'schen Bacillus beschrieben hat, die hier spontan in sehr alten Culturen auftraten, wo also die betreffenden Bacterien sehr lange Zeit auf erschöpftem Nährboden der Einwirkung ihrer eigenen Stoffwechselproducte ausgesetzt gewesen waren.

Alles in Allem ist es mir nicht zweifelhaft, dass es leicht ist, Platten, von denen die eine nur Cholera-, die andere nur Vibrio M.-Colonieen enthält, schon nach dem makroskopischen Anblick und sicherer noch unter dem Mikroskop zu unterscheiden. Dagegen möchte ich es für ausserordentlich schwierig, wenn nicht unmöglich halten, in einem Bacteriengemisch, wo unter zahlreichen Choleracolonieen vereinzelte Vibrio M.Colonieen enthalten sind, die letzteren, besonders wenn sie atypisch wachsen, in jedem Falle als solche zu erkennen. Ich füge hinzu, dass ich als typische Form des Gelatinewachsthums die stark verflüssigenden, Finkler-ähnlichen Colonieen betrachte. In solchen Fällen haben wir jedoch im Thierexperiment ein Mittel, welches unter allen Umständen uns erlaubt, die Differentialdiagnose zwischen Cholera und Vibrio M. mit aller wünschenswerthen Sicherheit zu stellen. Der Vibrio Metschnikoff ist nämlich, wie dies schon ausführlich von dem Entdecker Gamaleia nachgewiesen wurde, für eine ganze Reihe von Thieren in hohem Grade pathogen, und von Allem sind es die Tauben, welche geradezu ein Reagens für die uns beschäftigenden Vibrionen darstellen. Niemals habe ich bei dieser Thiergattung im Laufe einer sehr ausgedehnten Versuchsreihe eine Fehlimpfung beobachtet. Die minimalste Menge einer Reincultur der Gamaleia'schen Vibrionen, etwa so viel wie an der Spitze einer Platin-

${ }^{1}$ Archiv für Hygiene. Bd. VIII. S. 369. 
nadel hängen bleibt, genügt bei Impfung in den Brustmuskel, um inncrhalb 20 Stunden den Tod herbeizuführen. Bei der Section findet man alsdann regelmässig eine sofort sehr in das Auge fallende Anschwellung des geimpften Brustmuskels. Derselbe zeigt sich beim Einschneiden in grosser Ausdehnung gelblich verfärbt und nekrotisirt und ist von beträchtlichen Mengen einer blutigen Oedemflüssigkeit durchtränkt, die von Vibrionen wimmelt. Das Herz ist stets prall mit geronnenem Blute angefüllt, die Lungen sind blutreich, Leber und Milz anämisch und schlaff. Das Herzblut, sowie der ausgestrichene Organsaft enthalten ungeheure Mengen von Vibrionen. Der Darm ist meist blass und mässig mit graugelblicher Flüssigkeit von der Consistenz der Mehlsuppe angefüllt. Im Darminhalt finden sich bei der mikroskopischen Untersuchung zahlreiche abgestossene Epithelzellen, aber nur sehr spärliche Vibrionen. Oft werden dieselben in mikroskopischen Präparaten ganz vermisst, und man bedarf des Plattenverfahrens, um ihre Anwesenheit festzustellen. Gamaleia giebt an, dass nach Impfung mit seinem schwachen Virus im Darminhalt zablreiche Leukocyten zu finden seien. Ich habe etwas Derartiges nie zu bemerken Gelegenheit gehabt. In Uebereinstimmung mit Gamaleia habe auch ich gefunden, dass Tauben per os kaum inficirt werden können. So überstanden diese Thiere das Einflössen von $5^{\mathrm{ccm}}$ einer trüben Aufschwemmung von frischen Vibrio-M.-Agarculturen mit Bouillon, auch wenn vorher durch う̃ procent. Sodalösung für Alkalisirung des Kropf- und Mageninhaltes gesorgt war. Nur zwei von sechs in dieser Weise behandelten Thieren gingen innerhalb 24 Stunden zu Grunde. Hier fand sich die Lunge sehr blutreich, einzelne Läppchen derselben hatten eine dunkelrothe Farbe und waren luftleer; Ausstrichpräparate des Lungensaftes liessen geradezu enorme Mengen von Vibrionen erkennen, desgleichen zeigte sich das Herzblut reich an Vibrionen. Im Gegensatz dazu war der Darm blass; in seinem Inhalte waren mikroskopisch Vibrionen nicht nachweisbar, sogar im Kropf wurden nur noch sehr vereinzelte gekrümmte Bacterien unter einer Anzahl von anderen Mikroorganismen aufgefunden. Es gleichen diese Sectionsergebnisse durchaus denjenigen, welche von Gamaleia bei directer Einspritzung virulenten Blutes in die Luftrōhre der Hühner beschrieben sind, und man wird schliessen dürfen, dass in den oben angeführten Fällen die vibrionenhaltige Bouillon durch unzeitige Respirationsbewegungen gleichfalls in die Luftröhre und in das Lungenparenchym gelangt ist, von wo aus den Vibrionen der Weg in die Blutbahn offen stand.

Versuche an Hühnern habe ich nur in beschränkter Zahl gemacht. Ein erwachsenes und ein junges Huhn wurden mit den sehr vibrionenreichen Organen von Tauben gefüttert. Beide blieben gesund. Ferner 
injicirte ich zwui weiteren Hühnern und zwar gleichfalls einem erwachsenen und einem jungen Thiere je $1^{\mathrm{cm}}$ einer vibrioneuhaltigen Bouilloncultur in den Brustmuskel. Nur das Hühnchen ging zu Grunde und zeigte einen Obductionsbefund, der völlig dem der an Vibrio M. géstorbenen Tauben glich. Es fand sich dieselbe locale entzündliche Reaction, Verfïrbung der betreffenden Muskelpartieen, sanguinolentes Oedem mit zahlreichen Vibrionen; das Herzblut enthielt jedoch nur vereinzelte Exemplare derselben. Der Darm war blass, nur die Oberfläche der Schleimluaut zeigte eine fleckige Hyperämie; der Darminhalt liess mikroskopisch zahlreiche desquamirte Epithelien, doch keine Vibrionen erkennen.

Unter den Säugethieren erwiesen sich MLäuse für den Vibrio M. mu wenig empfänglich. Sie wurden zwar nach Impfung in die Schwanzwarzel mehrere Tage sichtlich krank, erholten sich jedoch alsdann wieder. l)agegen zeigte sich der uns beschäftigende Mikroorganismus fast eben so pathogen für Meerschweinchen als für Tauben. Der sicherste Infectionsmodus ist auch hier die subcutane Impfung. Ausnahmslos tïdtliche lufection vermochte.ich zu erzielen durch subcutane Injection eines Cubikcentimeter einer Aufschwemmung vou vibrionenhaltigem Taubenblut in Bouillon. Bei Einführung kleinerer Vibrionenmengen in das Unterhautzellgewebe wir der tödtliche Ausgang nicht so constant. Impfte ich beispielsweise die Thiere in derselben Weise wie die Tauben, nämlich mittelst des in-die Cultur getauchten Platindrahtes, so blieb immer eine gewisse Anzahl, etwa 10 Prozent am Iueben.

Die ersten Kirmkheitserscheinungen treten sehr bald nach der Impfung auf. Sehou nach 2 Stunden, wo die Thiere sonst noch ziemlich munter sind, giebt das Thermometer eine Erhöhung der Körperwärme um 1 bis $2^{0} \mathrm{C}$. an. Diese anfängliche Temperaturerhöhung ist jedoch nur vorübergehend and macht einem stetigen Sinken der Körperwärme Platz, wobei die Thiere unlustig werden und zusammengelauert unbeweglich dasitzen. Schliesslich fallt die Temperatur bis auf $33^{\circ} \mathrm{C}$, ja noch darunter, die hinteren Extremitäten der schwer kranken Thiere sind wie gelähmt, und 18 bis hüchstens 24 Stunden nach der Impfung erfolgt oft unter Muskelzuckungen der Tod.

Bei der Obduction tindet man ein von der Impfstelle ausgehendes massiges Oedem von sanguinolenter Beschaffenheit, welches oft über den halben Körperumfang sich erstreckt. Lungen hyperämisch, die Pleuren unthalten öfters ein klares seröses Exsudat, Herz prall gefüllt mit geronnenem Blut. Unterleibsorgane blass. Der Darm ist gleichfalls blass, der Darminhalt lässt mikroskopisch nur sehr spärliche Vibrionen erkennen, während die Oedemflüssigkeit, das Blut und der Organsaft sehr reich sind an diesen Mikroorganismen. 
Bei Meerschweinchen gelingt auch die Infection rom Darmcanal cus, doch genügt es nach meinen Erfahrungen nicht, wie Gamaleia angiebt, ihnen einfach eine virulente Bouilloncultur einzuflössen. Man muss vielmehr für Alkalisirung des Magens durch Sodalösung Sorge tragen und den Darm durch intraperitoneale Einspritzung ron Opiumtinctur ruhig stellen. Nach gelungener Infection findet man dann den Darm sehr stark entzündet und tief purpurroth gefärbt. Die entzündliche Reaction des Darmes ist sehr viel intensiver, als bei der artificiell erzeugten Meerschweinchen-Cholera, und die Vibrionen treten nicht allein im Darminhalt, sondern in reichlicher Anzahl im Herzblut der Thiere auf.

Ich glaube, die eben beschriebenen Thierexperimente sprechen nicht gerade für die Ansicht Gamaleia's, dass Vibrio H. und der Koch'sche Kommabacillus nichts Anderes sind, als „deux variétés physiologiques du même microbe". Zwar behauptet der russische Forscher, um die Beziehungen zwischen beiden Bacterienspecies möglichst eng erscheinen $\mathrm{zu}$ lassen, dass auch bei dem Vibrio $M$. bei jedem Impfmodus der Darmcanal die Hauptlocialisationsstelle darstelle, eine Auffassung, die auch in dem von ihm gewählten Namen gastro-entérite cholérique unverhüllt zu Tage tritt. Doch kaun ich mich nach meinen Thierversuchen dem nicht ohne Weiteres anschliessen.

Eine wirkliche, unzweifelhaft entzündliche Darmaffection konnte ich uur in den Fällen constatiren, wo der Darm entweder selbst die Eingang:pforte für die Vibrionen gewesen war, oder wo er doch, wie beispielsweise bei intraperitonealer Infection, direct unter der entzündungserregenden Wirkung der Mikroorganismen gestanden hatte. Im Uebrigen verläuft die durch den Vibrio M. bedingte Infection so gut wie ausschliesslich in der Blutbahn und schliesst sich eng an schon längst bekannte Septicämieen an, von denen ich hier nur an die Hühnercholera und die Stäbchensepticämie der Mäuse erinnern will. Nach bekannten Analogieen möchte ich für die neue, von Gamaleia entdeckte Thierkrankheit den Namen Vibrionensepticämie vorschlagen, der jedenfalls mehr den thatsächlichen Verhältnissen entspricht. Bei subcutaner oder intramusculärer Impfung, ferner bei Infection von den Luftwegen aus findet man regelmässig den Darm blass, die Schleimhaut höehstens etwas hyperämisch; der Darminhalt entfält nur sehr spärliche Vibrionen, ein Befund, der lebhaft mit der Unzahl der im Blute cursirenden Mikroorganismen contrastirt.

Gamaleia hatte gefuuden, dass alte Hühner, welche sonst auf keine Weise künstlich inficirt werden können (wohl aber spontan erkranken), sterben, Tenn man ihnen grössere Mengen, $1 \mathrm{ccm}$ beispielsweise, ron ribrionenhaltigem Taubenblut direct in die Lungen oder in die Luftröhren 
injicirt. Giamaleia glaubt sich in Folge dieser Beobachtungen, deren Richtigkeit ich im Uebrigen nicht bezweifeln will, für berechtigt, den Infectionsweg von der lungenoberfläche aus als "le mode naturel" zu erklären. $W_{0}$ in aller Welt aber tindet ein Thier Gelegenheit, derartigu Mengen virulenten Materiales in seine Luftwege aufzunehmen, wenn sio ihm nicht die Hand des Experimentators einspritzt? In der Natur gelangt nur Staub in die Lungen, und hätte Gamaleia den natürlichen Infectionsmodus nachahmen wollen, so wäre es ihm ein Leichtes gewesen, getrocknete und gepulverte Culturen seiner Vibrionen, am besten sporeuhaltiges Material, seine Versuchsthiere inhaliren zu lassen. Dass solch' ein Versuch, auch wemn er wirklich gelungen wäre, aber immer noch nichts besagen würde für die Aetiologie der Cholera asiatica, wie Gamalei، uns glauben machen will, wird mir so lange unbestreitbar sein, als Dauerformen des Koch'schen Bacillus, welche dem Eintrocknen Stand halten, uoch nicht bekannt sind.

Ferner giebt Gamileia an, seinen Vibrio als Krankheitserreger in einem Falle ron Cholera sporadica beim Menschen gefunden zu haben. Es liegt mir ferne, für Odessil eine derartige Möglichkeit völlig auszuschliessen, aber über allen Zweifel erhaben ist die Angabe des russischen l'or'schers sicherlich nicht. Gamaleia fütterte ein junges Huhn mit den reiswasseräbnlichen Stühlen des Cholerischen und sab sein Versuchsthier 3 Tage darauf au typischer „Gantro-entérite cholérique" zu Grunde gehen.

Es ist hier runächst die Möglichkeit einer Spontan-Infection nicht ron der Hand zu weisen; andererseits zugegeben, dass die Vibriunen thatsïchlich in dem Darminhalt rorhanden waren, was beweist uns, dass grade sie die schwere tirkrankung des Menschen verursachten. Es könnte sich ja um ein zufailliges Vorkommen des Vibrio II. im Darminhalt gehandelt haben, ïhnlich wie Fincler seiner Zeit den nach ihm benannten Vibrio gleichfalls im Stuhl eines an Cholera sporadica Gestorbenen fand, wo doch, wie wir jetat wissen, vou einem Ciusalzusammenhange zwischen der choleraähnlichen Erkrankung und der Anwesenheit des betreftenden Bacterium sicher nicht die Rede sein konnte. Man wird also zunächst wohl noch mit seinem Urtheil zurückhalten müssen, bis Gamaleia an einer grossen Zahl von Fällen die stete Anwesenheit seiner Vibrionen nachgewiesen hat, und zwar dürte der Befund ganz vereinzelter, nur durch das Thierexperiment nachweisbarer Vibrionen, den Amnahmen Gamaleia's entgegen, nicht genügen, sondern man wird darauf bestehen müssen, dass die krankmachenden Mikroorganismen wenigstens doch hin und wieder in einer Menge gefunden werden, welche der Schwere der durch sie verursachten Krankheit entspricht. Daggegen, dass dieser Nachweis leicht zu erbringen sein wird. sprechen die zahlreichen stets negativen Resultate Koch's und seiner 
Mitarbeiter, welche auch durch Gamaleia's Einwendungen gegen die Plattenmethode nicht entkräftet werden. Colonieen, welche so lebhaft an Cholera asiatica erinnern, hätten den spähenden Augen so vieler und guter Beobachter nicht entgehen können.

Die bisher erörterten Thatsachen und Erwägungen machen es schon recht unwahrscheinlich, dass zwischen Cholera asiatica und Vibrio Metschnikoff allzu nahe Beziehungen bestehen; doch bedürfen noch einige positive Angaben Gamaleia's der eingehenden Berücksichtigung, zumal deren Bejahung oder Verneinung die Angelegenheit in diesem oder jenem Sinne endgültig entscheiden dürfte. Gamaleia glaubte den Beweis für die Identität der Cholera asiatica und der von ihm entdeckten Vibrionenart erbracht zu haben und zwar gestïtat auf folgende Behauptungen: 1. Es ist möglich, durch geeignete Methoden den Koch'schen Irommabacillus so umzuzüchten, dass er bei Tauben eine schnelltüdtende Supticämie hervorbringt, die alsdann von der gastro-entérite cholérique nicht zul unterscheiden ist. 2. Es gelingt durch Präventivimpfungen mil Cholera asiatica Thiere gegen die Vibrionensepticämie immun \%u machen Ind vice versa. Die erste Behauptung ist ron Nocht und mir als unbegründet zurückgewiesen worden, ${ }^{\mathfrak{l}}$ mit der zweiten werden wir uns im Folgenden eingehender zu beschäftigen haben. Zunächst war zu ermitteln, ob Thiere gegen die Vibrionensepticämie immun gemacht werden können, und ich fand in der That, im Einklange mit Gamaleia, dass es unschwer gelingt, Meerschweinchen und Tauben durch Injection sterilisirter Bouillonculturen in Dosen, welche zwar einen deutlich toxischen Effect haben, aber noch vertragen werden, gegen die Wirkung des lebenden Giftes zu schützen. Genauer studirte ich die fraglichen Verhältnisse bei Meerschweinchen.

Die benutzten Bouillonculturen wurden bei Brüttemperatur gezüchtet. Es kamen sowohl junge, 3 bis 5 Tage alte Culturen, als auch solche, die bis zu 20 Tagen bei $37^{\circ} \mathrm{C}$. gestanden hatten, zur Verwendung. Sterilisirt wurden sie durch halbstündiges Erhitzen im Dampfkochtopf, wonach, wie Controlimpfungen auf schräg erstarrtem Agar ergaben, alles Leben in ihnen abgetödtet war. Die in dieser Weise sterilisirten Culturflüssigkeiten zeigten nun sowohl bei subcutaner als auch intraperitonealer Einspritzung schon in verhältnissmässig geringen Dosen von 1 bis 2 ecm eine sehr ausgesprochene krankmachende Wirkung, und zwar nahm der toxische Effiect sichtlich zu mit dem Alter der Cultur. Während von jungen, bis 5 Tagu alten Culturen, 3,4 ja $5^{\mathrm{cm}}$ intraperitoneal noch eben vertragen wurden, führte die Injection von nur $2^{\mathrm{com}}$ einer 20 Tage alten Cultur in der

${ }^{1} \mathrm{Vgl}$. diese Zeitschrift. 1889. S. 259. 
Mehrzahl der Fälle zum Tode: Gleich nach der Injection werden die Versuchsthiere unlustig und sitzen zusammengekauert in eine Ecke zusammengedrängt. Die in recto gemessene Körperwärme beginnt zu sinken und kann inuerhalb 1 bis 2 Stunden schon zwei und mehr Grade unter die Norm gefallen sein. Ist die Dosis nun nicht tödtlich, so beginnen die Thiere sich jetzt wieder zu erholen, während gleichzeitig die Temperatur rapide ansteigt und sich in kurzer Zeit um zwei und mehr Grade über die Norm erhebt, so dass unter diesen Umständen innerhalb 3 bis 4 Stunden Schwankungen der Eigenwärme um $4^{0}$ und mehr beobachtet werden können. Unter allmählichem Abklingen der Fiebertemperatur verschwinden nun ziemlich rasch alle lírankheitserscheinungen und, nach Ablauf von 24 Stunden sind die Thiere wieder so munter, wie zuror. Ich füge hinzu, dass bei sehr kleinen Dosen ( 1 cm 5 Tage alter Cultur) die primäre Temperaturerniedrigung nur sehr gering ist, so dass anscheinend sofort nach der Injection sich ein nur wenige Stunden dauerndes Fieber einstellt.

Bei stärkeren, letalen Dosen steriler Bouillonculturen bleibt das zweite Stadium der fieberhaften Reaction ganz aus, die Temperatur sinkt andauernd immer tiefer und tiefer, bis schliesslich oft erst nach 36 bis 48 Stunden unter den Frscheinungen tiefster Prostration und bei Körpertemperaturen von $33^{\circ} \mathrm{C}$. und darunter der Tod eintritt. Bei der Section habe ich mich regelmässig sowohl durch die mikroskopische Untersuchung der Lï̈rpersïfte, als auch durch Ueberimpfen derselben aut Agaragar von dem vollständigen Fehlen von Miliroorganismen überzeugt. Das Obductionsbild war von der Abwesenheit der Vibrionen abgesehen identisch mit dem dex Vibrioneusepticämie; nur zeigte die Leber oft sehr auffallende pathologische Abweichungen. In Fällen, wo in Folge der Vergiftung der Tod sehr rasch eingetreten war, war die Leber nur wenig vergrössert, die einzelnen Leberläppchen erschienen vergrössert und zeigten einen helleren, gelbröthlicheu peripherischen und rothbraunen centralen Theil. Hatte die Vergiftung einen protrahirten Verlauf genommen (48 Stunden und mehr), so war die Anschwellung der Leber sehr viel beträchtlicher, die Läppchenzeichnung war undeutlich, die Farbe der gesammten Ieber hellgelb, ihre Consistenz sehr brüchig. Als Ursache dieser Veränderung liess sich durch das Mikroskop eine mehr oder weniger beträchtliche Verfettung der Leberzellen erkennen. Letztere waren mit Fetttröpfchen ron dem verschiedensten Durchmesser, von grossen, die halbe Zelle ausfüllenden Tropfen bis zu den feinsten, noch eben erkennbaren Stäubchen hinab, angefüllt. Ihr Kíern war meist durch Essigsäure noch kenntlich zu machen.

Die so enorm giftigen 20 Tage alten Bouillonculturen zeigten uun 
einen überraschend hohen Alkalescenzgrad. Während die frische Bouillon $7 \mathrm{~cm}$ Normal- $\mathrm{H}_{2} \mathrm{SO}_{4}$ pro Liter zur Neutralisirung bedurfte, erforderte die gleiche Menge der toxischen Bouilloncultur $35^{\mathrm{cem}}$, ein Beweis, dass eine sehr beträchtliche Menge basischer Körper neu gebildet war. Es war nun recht gut möglich, dass ein Theil der toxischen Wirkung auf Rechnung des freien Alkali kam. Ich brachte daher einige sterile Bouillonröhrchen durch Zusatz von kaustischem oder kohlensaurem Ammoniak auf dell doppelten Alkalescenzgrad der toxischen Bouillon und injicirte Meerschweinchen Mengen von $4^{\mathrm{com}}$ in die Bauchhöhle, jedoch ohne dass die Meerschweinchen $415^{\mathrm{grm}}$ schwer, $2^{\mathrm{cm}}$ toxische Bouillon intraperitoneal, nicht neutralisirt.

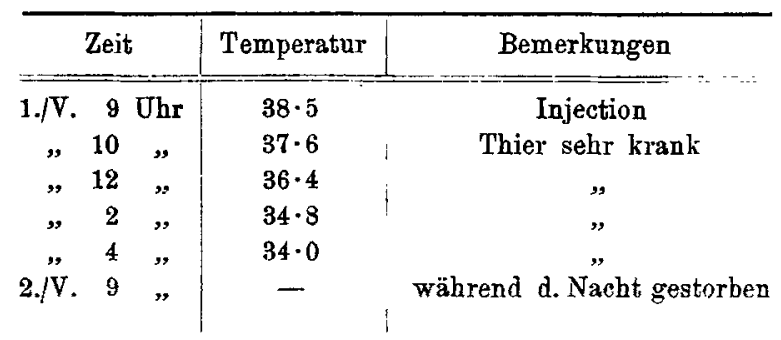

Weerschweinchen $460 \mathrm{grm}$ schwer, 2 cem derselben Bouillon intraperitoneal: durch $\mathrm{HCl}$ neutralisirt.

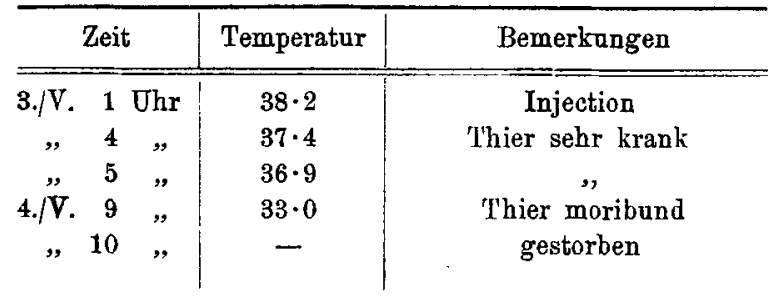

Heerschweinchen $425 \mathrm{grm}$ schwer, $2^{\mathrm{ccm}}$ derselben Bouillon intraperitoneal, durch $1 / 10$ Normal- $\mathrm{H}_{2} \mathrm{SO}_{4}$ neutralisirt.

\begin{tabular}{|c|c|c|c|c|}
\hline \multicolumn{3}{|c|}{ Zeit } & Temperatur & Bemerkungen \\
\hline 1./V. & 9 & Uhr & $38 \cdot 2$ & Injection \\
\hline ", & 12 & s & $37 \cdot 3$ & Thier sehr krank \\
\hline ", & 5 & , & $36 \cdot 8$ & Thier beginnt sich $\mathrm{z}$ erholen \\
\hline $2 . / \mathrm{V}$ & 9 & , & $36 \cdot 8$ & Thier ziemlich munter \\
\hline$"$ & 3 & " & $39 \cdot 4 !$ & \\
\hline $3 . / \mathrm{V}$ & 9 & , & $39 \cdot 1$ & 'l'hier ganz munter' \\
\hline 4./V & 4 & $"$ & $\begin{array}{c}38 \cdot 8 \\
\text { normal }\end{array}$ & $"$ \\
\hline
\end{tabular}


Versuchsthiere erkrankten. Andererseits neutralisirte ich die toxische Bouillon durch Chlorwasserstoffsäure oder Schwefelsäure und hierbei ergab sich das ganz unerwartete Resultat, dass die Salzsäure den toxischen Effect in keiner Weise beeinträchtigte, während der Schwefelsãurezusatz die Giftwirkung zum grossen Theil aufhob. Das Interesse, welches diese Beobachtung beansprucht, wird es entschuldigen, wenn ich einen derartigen Versuch in extenso anführe, wobei ich hinzufüge, dass eine Wiederholung desselben ganz identische Resultate ergab. (Vgl. Tabelle S. 358.)

Wie hier die Schwefelsäure wirkt, vermag ich zur Zeit noch nicht zu sagen, möglicher Weise durch Bildung gepaarter Verbindungen, die ungiftig, bezw. weniger giftig sind. Die genauere chemische Untersuchung der giftigen Stoffwechselproducte des Vibrio M. behalte ich mir vor, nur soviel habe ich noch ermittelt, dass das giftige Princip nicht flüchtig ist, da das Destillat der toxischen Bouillonculturen auch in Mengen von 5 cm Meerschweinchen nicht einmal krank macht.

Für die Zwecke der vorliegenden Arbeit genügte mir der Nachweis, dass es in der That gelingt, durch mehrmalige, in Pausen von 1 bis 2 Tagen wiederholte Injection sterilisirter Culturen Meerschweinchen und Tauben immun zu machen, und zwar tritt diese Immunität erst etwa 14 Tage nach Beginn der Injectionen in Wirkung, da Thiere, welche vor Ablauf dieser Frist mit den lebenden Bacterien inficirt wurden, zu Grunde gingen. Da es mir darauf ankam, den sichersten Infectionsmodus bei den Controlimpfungen anzuwenden, so bediente ich mich zur Constatirung der erlangten Immunität subcutaner Injectionen von vibrionenhaltigem Taubenblut, überzeugte mich jedoch, dass auch bei Einführung des Virus in den Darmcanal die Infection ausbleibt.

Schon früher habe ich angegeben, dass einzelne Meerschweinchen die Impfung mit Vibrio Metschnikoff-Culturen überstehen. Letztere erwerben dadurch, wie Gamaleia gleichfalls schon gefunden hat, eine nach meinen bisherigen Beobachtungen absolute Immunität gegen jede Infection mit dieser Bacterieuart. Untersucht man nun den Krankheitsverlauf genauer einmal bei Meerschweinchen, die durch Injection sterilisirter Culturen immun geworden sind, und andererseits bei solchen, die von rornherein sich refractär verhalten, so findet man eine bemerkenswerthe Uebereinstimmung. Es entwickelt sich nämlich an der Impfstelle zunächst ein ziemlich starkes entzündliches Oedem. Gleichzeitig bekommen die Thiere lebhaftes Fieber; während num aber bei den nicht immunell Thieren die Temperaturerhöhung bald einer stetigen zunehmenden Eruledrigung der Körperwärme Platz macht, dauert bei den immunen und lefractären Thieren das Fieber all und erbält sich mehrere, 2, 3, auch 4 Tage auf seiner Höhe. Dabei sind die Thiere ziemlich munter und 
fressen. Die localen Entzündungserscheinungen bilden sich indess langsam zurück; gewöhnlich kommt es im Centrum der Entzündungsgeschwulst zu nekrotischer Abstossung kleinerer Hautpartieen, worauf unter Narbenbildung vollständige Heilung eintritt. Interessant ist der Parâllelismus der Schwankungen der Körperwärme bei Injectionen sterilisirter Culturen und bei Infection mit dem lebenden Virtus. Bei der Infection werden ja immer nur sehr geringe Mengen der giftigen Stoffiwechselproducte mit übertragen; die Bildung der letzteren im Thierkörper hält sodann gleichen Schritt mit der Vurmehrung der Vibrionen. Man wird daher zunächst auch nur die Wirkung minimaler Giftdosen, die, wie wir früher sahen. eine primäre Fieberwirkung hervorrufen, bemerken können. Bietet nım der inficirte Organismus den Bacterien einen guten Nährboden, so werden sich dieselben stark vermehren, viel Gift produciren, und wir gewahren in der nun sich einstellenden Temperaturerniedrigung denselben toxischen liffect, wie er wuch durch die Injection alter, giftreicher Culturen hervor-. gerufen wird. Ist digegen der Organismus von voruherein, oder in Folge vorhergegangener Schutzimpfungen nicht geeignet für das Wachsthun der Vibrionen, so wird auch deren Giftprodnction immer nur gering sein können; so erklïrt sich ungezwungen das Andauern yder Fiebertemperatur und das Ausbleiben der Temperaturerniedrigung. Uebrigens halten sich die Vibrionen auch im immunen Thierrörper beträchtlicho Zeit. So vermochte ich díeselben noch nach 90 Stunden durch das Plattenverfahren aus der Oedemflüssigkeit' der Impfstelle zu züchten bei einem Meerschweinchen, das schon zwei Impfungen mit lebenden Bacterien überstanden hatte. Einschluss der Vibrionen in Micro- oder Macrophagen habe ich nie bemerkt. Durch einen so ling andauernden Aufeuthalt im immunen Thierkürper büsst nun der Vibrio M. von seiner Virulenz für Meerschweinchen etwas ein, so dass alsdann nur noch etwa die Hälfte der geimpften Thiere erliegt, wilhrend eine Herabminderung der Virulen\% für Tauben in keiner Weise nachweisbar war.

5 Meerschweinchen, die ich nach den oben beschriebenen Methoden immunisirt hatte gegen die Gamaleia'schen Vibriunen, wurden nun nach der Koch'schen Methode mit Cholera inficirt. Davon gingen vier an typischer Cholera zu Grunde, während eines auch mehrfach wiederholten Cholerainfectionen Trotz bot, obwohl es jedes IIal sehr krank wurde und eine st:rke Erniedrigung seiner Kö̈rpertemperatur erkennen liess. Es entspricht dieses Resultat durchaus der Mortalität, wie wie auch sonst bei der Inficirung von Meerschweinchen mit Cholera unter den günstigsten Verhältnissen beobachtet wird. Immune Tauben konnte ich auf ihr Verhalten gegen die Cholera asiatica nicht prüfen, da sie der Cholerainfection, wie Tocht und ich fanden, kitum zugänglich sind. 
Dagegen war es ja sehr leicht, Tauben und Meerschweinchen, welche mit Cholera asiatica in der mannigfachsten Weise vorbehandelt waren, daraufhin zu prüfen, ob sie nun gegen die Vibrionensepticämie geschützt seien. Das Resultat war in allen Fällen negativ, d. h. die Versuchsthiere erlagen sämmtlich unter den bekannten Irrankheitserscheinungen innerhalb 24 Stunden der Septicämie. Ich möchte an dieser Stelle Herrn Stabsarzt Dr. Nocht meinen Dank aussprechen für die Liebenswürdigkeit, womit er sowohl die Schutzimpfungen als auch die Controlimpfungen mit Cholera übernommen hat. Was zunächst die Tauben anbetrifft, so erhielten sie als Prärentivimpfung "einmal oder mehrmals einen ganzen Cubikcentimeter trüber Bouillonilufschwemmung von frisehen CholeriAgarculturen in den Brustmuskel injicirt.

Frühestens 14 Tage nach diesen Injectionen bekamen die Tauben eine Platinöse von Vibrio Metschnikoff-Reincultur subeutan und gingen alsdann sämmtlich innerhalb 18 bis 20 Stunden unter dem: typischen Bilde der Vibrionensepticïmie zu Grunde.

Bei Meerschweinchen versuchte ich die Immunisirung nach drei verschiedenen Methoden:

1. Eine Anzahl von Thieren erhielt genau nach dem bei dem Vibrio $\mathrm{NI}$. befolgten Modus sterilisirte Cholerabouillon-Culturen, die 5 Tinge bei Brüttemperatur gezüchtet und alsdann im Dampfliochtopf durch hialbstündiges Erhitzen abgetödtet waren, intraperitoneal in Ilengen ron 2 bis $4^{\mathrm{cm}}$. Diese Injectionen wurden 4 bis 5 Tage hintereinander wiederholt.

2. In einer zweiten Versuchsreihe erhielten die Thiere eine einmalige subcutane Injeetion von $1 \mathrm{cum}$ einer dicken Bouillonaufschwemmung ron frischen Cholera-Agarculturen.

3. Eine Anzahl von Meerschweinchcu, welche die Cholerainfection rom Darm alls nach dem Koch'schen Verfahren überstanden hatten, wurden inuf ihr Verhalten gegen die Vibrionensepticämie geprïft.

Die Controlimpfung geschah, wie bei den immunen MetschnilioffThieren, durch subcutane Einspritzung eines Gemisches von vibrionenhaltigem Taubenblut und Bouillon uud hatte ausnahmslos den Effect, dass die Thiere innerhalb 24 Stunden einer durehaus typischen Vibrionensepticämie erlagen.

Nach diesen Resultaten glaube ich mich berechtigt, behaupten zu dürfen, dass eine wechselseitige Immunität zwischen Cholera asiatica und Vibrio Metschnikoff nicht existirt. Wie die so abweichenden Resultate Gamaleia's zu erklären sind, entzieht sich natürlich der Beurtheilung. Nur möchte ich auf eine Thatsache aufmerksam machen, die ich im Beginn meiner Versuche feststellen ronnte. Ton der Idee geleitet, dass die Gamaleia'schen Vibrionen, deren Stoffirechselproducte doch vielfiche 
Aehnlichkeit mit denen der Cholera besitzen, den Taubenkörper vielleicht so umzuwandeln vermöchten, dass auch die gleichzeitig mit eingebrachten Cholerabacillen darin zu gedeihen im Stande wären, injicirte ich Tauben Gemische, die aus enormen Mengen von Cholerabacillen und nur vereinzelten Metschnikoff-Vibrionen bestanden. Der Effect war aber nicht der erwartete. Das Blut der betreffenden Thiere enthielt nur die letzteren Vibrionen, während die Cholera trotz ihrer anfänglichen enormen Ueberlegenheit an Zabl zu Grunde gegangen waren. Gelangt also durch einen unglücklichen Zufall auch nur ein Vibrio M. in eine Choleracultur, so wird trotzdem bei der Impfung von Thier zu Thier die Cholera ganz aus dem Felde geschlagen werden und schliesslich eine Reincultur der Metschnikoff-Vibrionen resultiren. - Als Resultate meiner Untersuchungen komme ich zu folgenden Sätzen:

1. Cholera asiatica und Vibrio Metschnikoff sind morphologisch, besonders aber durch die Form ihrer Colonieen in Gelatineplatten unterschieden.

2. Beide Bacterienspecies geben unter gleichen Verhältnissen die ('holerarothreaction. Trotzdem ist es leicht, beide Mikroorganismenarten zu unterscheiden, da

3. der Vibrio Metschnikoff für Tauben ganz ausserordentlich pathogen ist, während die Cholera für diese Thiere so gut wie gar keine Virulenz besitzt.

4. Es ist möglich, Meerschweinchen und Tauben gegen Vibrio M. zu immunisiren.

5. Hine wechselseitige Immunität der mit Vibrio M. vorgeimpften Thiere gegen Choleri asiatica und umgekehrt besteht nicht.

\section{Erklärung der Photogramme.}

\section{(Tafel III.)}

Fig. 1. Gelatineplatte ron Vibrio M. genau 24 Stunden alt, bei Zimmertempe. ratur $\left(20^{\circ} \mathrm{C}\right.$.) gewachsen, natürliche Grösse.

Fig. 2. Gelatineplatte von Vibrio M., etwa 20 Stunden alt, bei 50 facher Ver. grössserung.

Fig. 3. Stichcultur des Vibrio M. in 10 procentiger Gelatine.

Fig. 4. Eine der betreftenden Colonieen bei 100 facher Vergrösserung.

Fig. 5. Herzblut einer an Vibrionensepticämie gestorbenen Taube, Deckglaspräparat gefärbt mit Fuchsin. Apochromat Zeiss $2^{\mathrm{mn}}$, Apertur $1 \cdot 40$. Vergrösserung 1000 fach.

Fig. 6. Klatschpräparat von Vibrio M.-Gelatineplatten. Fuchsinfärbung. Ver-

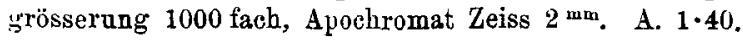

